\title{
POR UNA COMUNICACIÓN PENSADA DESDE LAS NECESIDADES DE LAS COMUNIDADES
}

\section{[ CLemenCIA RODRíGueZ ] ]}

Profesora, Departamento de comunicación, University of Oklahoma. Ph.D., Ohio University.

clemencia国ou.edu

\section{[ MELBA QUUIJANO ]}

Profesora de la Facultad de Comunicación social y periodismo,

Universidad Pontificia Bolivariana (Bucaramanga). Magister

en planificación y administración del desarrollo regional,

Universidad de los Andes.

melbaqui国gmail.com

Recibido: febrero 26 de 2014

Aceptado: abril 18 de 2014 
Con base en cinco investigaciones sobre comunicación comunitaria, este artículo desarrolla una reflexión sobre el campo de la Comunicación para el Cambio Social. El artículo propone una tercera vía a medio camino entre la Comunicación para el Desarrollo y la Comunicación Alternativa, un viraje fundado en el pensar desde las necesidades de información y comunicación de las comunidades, en vez de pensar la comunicación desde las verdades últimas de la teoría. Vista así, la Comunicación para el Cambio Social surge como un campo que toma lo mejor de estas dos tradiciones, pero no se casa con las verdades absolutas de ninguna.

Palabras clave: Comunicación alternativa, comunicación para el cambio social, investigación etnográfica

\section{REFLECTIONS ON A NEED-BASED DEFINITION OF COMMUNICATION} FOR SOCIAL CHANGE

\section{ABSTRACT}

Based on five community communication research studies, this article develops a reflection about the field of Communication for Social Change. The paper proposes a third way in-between the schools known as Communication for Development and Alternative Communication, a shift in perspective founded on prioritizing the community's information and communication needs, over prioritizing theoretical or conceptual principles. Seen this way, Communication for Social Change emerges as a field that incorporates the best of both traditions, and yet does not commit to the theoretical truths of either one.

Keywords: Alternative communication, Communication for social change, ethnographical research.

\section{CINCO EXPERIENCIAS DE CAMPO}

\section{Caso uno: concurso navideño en Caquetá}

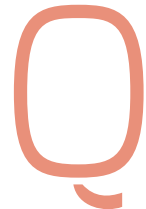
uisiéramos comenzar más desde la experiencia y las lecciones aprendidas, que desde la teoría. Entonces comencemos con cinco situaciones en las que podemos ver claramente cómo los medios se están usando para responder a las necesidades de comunicación que se viven en las comunidades. Los cinco casos que siguen a continuación provienen de investigaciones etnográficas en el campo de la comunicación para el cambio social (Lim 2012 y Rodríguez 2011).

Miremos cómo se vive esto a nivel local. Belén de los Andaquíes, un pequeño pueblo de seis mil habitantes se siente como un pueblo fantasma. La gente está aterrada, y las costumbres habituales del pueblo - los vecinos conversando con los vecinos, los amigos tomando unas cervezas en la tienda al caer la tarde, los niño/as jugando en el parque central, los adolecentes coqueteando en la plaza del pueblo- ya no se ven. Aterrados por la situación de militarización, guerra e informantes locales, la gente se encierra en sus casas, los negocios cierran a las seis de la tarde, todos abandonan los espacios públicos, todos sospechan de todos, se repliegan a los espacios privados. Belén pasa de ser una comunidad a ser un conglomerado de individuos aislados. Esto preocupa a los líderes de Radio Anda- quí, la emisora comunitaria del pueblo. Y entonces, hacia 1997, un año después de las marchas cocaleras, cuando el conflicto ha bajado de intensidad pero la esfera pública aún está abandonada, Radio Andaquí diseña una estrategia de comunicación para el cambio social. La meta es volver a sacar a la gente de lo privado a lo público y, de alguna forma, generar esas conversaciones entre vecinos y amigos, todas esas interacciones interpersonales que constituyen el tejido social de una comunidad. La idea es hacer algo con la emisora para contrarrestar el impacto de la guerra en el tejido social. Radio Andaquí diseña un concurso navideño de decoración del pueblo. Los lineamientos del concurso son claros: quien concursa no es la familia o la casa, tiene que ser la cuadra. Es importante enfatizar el significado de esta estrategia; definir el concurso por cuadras implica que los vecinos de la cuadra van a tener que interactuar entre ellos para poder concursar. Pronto se ve cómo los vecinos se reúnen para decidir cómo van a decorar su cuadra; la gente comienza a trabajar en las decoraciones, después del trabajo se ven los grupos pintando, las puertas de las casas se dejan abiertas, la gente entra y sale, se prestan herramientas, se guardan las pinturas en una casa, las brochas en la otra. Radio Andaquí usa su radiocicleta, una unidad móvil montada en una bicicleta de dos puestos, con micrófono y transmisor, para transmitir desde las cuadras más avanzadas. La emisora describe cómo la cuadra de los Machuca está decorando con unas casitas hechas con cartones de hue- 
vos. Pronto, los vecinos de otras cuadras se acercan a la cuadra de los Machuca a mirar ellos mismos las casitas. La siguiente noche, la radiocicleta transmite desde otra cuadra, esta vez es la cuadra del colegio donde la decoración está inspirada en un tema de invierno, algo bien curioso en la Amazonía colombiana, donde nadie ha visto jamás la nieve. Y así, paso a paso, Radio Andaquí va generando todo tipo de interacciones entre los vecinos, reconstituyendo el tejido social, sacando a la comunidad de su aislamiento y su estado de terror colectivo. El 23 de diciembre Radio Andaquí anuncia la cuadra ganadora del concurso e incluso el premio es diseñado con miras al cambio social: es un lechón y todo lo necesario para una gran fiesta ofrecida por la cuadra ganadora a todos en el pueblo (Rodríguez 2011, pp. 63 - 66). comunidad. La comunidad católica homogénea de antes se ha fragmentado en grupos evangélicos, de Testigos de Jehová y Adventistas y hay mucha hostilidad y conflictos entre los grupos. Pérez usa la emisora para activar procesos de diálogo desde la diferencia, y explica una de sus estrategias:

Eso de la construcción de lo público en la radio es más bonito. Es que mucha persona estúpida que accede a producir radio cambia, porque la producción radial le permite meterse ya de verdad en lo que cotidianamente no veía, y entonces lo ve con otros ojos. Puerto Inírida es zona de evangélicos, porque es región de colonización; es el municipio más joven del país, pues tiene 36 años. Allí son muy toscos con la misión, compiten mucho por la cantidad de feligreses, entonces el púlpito es un espacio sórdido, y es puro monólogo. Eso genera agresivid. Cuando surge la radio en el escenario municipal, los llamamos a todos: 'vengan para acá, pues nuestra propuesta es que ustedes son muy interesantes todos, entonces hay un espacio en la emisora para ustedes'. Sacamos una franja pequeñita, de cinco minutos, de seis de la mañana a seis y cinco. El lunes hablan los católicos, el martes el movimiento misionero mundial, el miércoles los adventistas, el jueves la Gran Sion de amor, y los viernes los testigos de Jehová. Pero no pueden ni echarse los unos contra los otros, ni la Iglesia Católica promover la semana santa en la emisora, porque se trata de reflejar al pueblo, a todas las identidades en la parrilla de programación. Y como lo Católico no es lo único, puede que sea lo más rimbombante, pero no lo único, entonces la emisora les garantiza a todas las comunidades religiosas que hay equidad. Como se portaron bien, ampliamos la franja a 15 minutos. Se llamó En el Cuarto con Dios, o sea en el cuarto de hora, eso lleva como tres años y hace dos se amplió a una hora, de seis a siete, con cosas muy bellas. Eso ya es una franja, iy entre ellos se oyen! Y cuanto más se oyen, más inteligentes se vuelven porque tienen que tener en cuenta lo que dijo el otro ayer. Mire, eso de la religión a mi me vale mierda, ipero esto es tan bonito! Es un ejemplo tan bacano de convivencia, y ha servido tanto... Por ejemplo en los colegios ya no se ven los niveles de agresividad tan tenaces que se veían antes. Yo creo que así como a uno en las emisoras comerciales le ponen a Alejandro Saenz todos los días para que se vuelva un éxito, se lo ponen cada ratico, el hecho de que esto de la discusión religiosa sea una franja, les transmite el mensaje de '¿cuál es el problema de escuchar a uno que es diferente a usted y que cante cosas que yo no canto?' Son espacios de participación y convivencia responsable (Pérez, 2004). 
Esto es comunicación para el cambio social. Es decir, un acercamiento a la comunicación que nos inserta dentro de la comunidad, nos obliga a mirar a la comunidad desde sus necesidades de comunicación e información. Y es desde allí desde donde podemos jalonar tecnologías, reinventar funciones de los medios, re-pensar las relaciones entre el medio y la audiencia, entre productores y receptores. De estos dos casos es importante resaltar un par de elementos: el primero es que en los dos casos vemos cómo estos comunicadores comunitarios han diseñado complejas estrategias de comunicación para activar, para generar procesos sociales de cambio. Es decir, son procesos hiper-diseñados. Las tecnologías mediáticas se usan de formas muy controladas. Sí, son medios abiertos a la participación comunitaria, pero desde una serie de estrategias diseñadas cuidadosamente, en términos de formatos, usos de unidades móviles, diseño de la programación, etc.

Segundo, la sabiduría de estos comunicadores comunitarios no es ni gratis ni improvisada. Son comunicadores que se han ido especializando por años y años en afinar sus capacidades para diseñar este tipo de estrategias de comunicación para el cambio social. Y tercero, para poder lograr este tipo de diseños tan sofisticados, estos comunicadores comunitarios, como Guillermo Pérez o como los radialistas de Radio Andaquí, están fuertemente arraigados en sus comunidades. Conocen tan bien el tejido social de su comunidad, que comprenden muy bien cuáles son exactamente las necesidades de información y comunicación. Comprenden también cómo usar las tecnologías mediáticas en cada caso. Estos comunicadores comunitarios operan en sus comunidades como etnógrafos permanentes, siempre yendo y viniendo entre los diferentes sectores de la comunidad, explorando espacios para la comunicación, posibilidades de utilizar tal o cual tecnología mediática aquí o allá, poniendo atención a nuevas oportunidades de abrir un espacio de comunicación, de diálogo, o confirmando también cuándo un espacio que existía desaparece. Todo esto, claro, a punta de dosis inmensas de creatividad. Finalmente, es importante resaltar cómo en ninguno de estos casos se utilizaron fórmulas.

\section{Caso tres: Santa Rosa del Sur y el rescate de José Botello}

El tercer caso viene de la región conocida como el Magdalena Medio, en el centro del país. Aquí funciona AREDMAG, una red de más o menos doce emisoras comunitarias. El siguiente testimonio surge de una de estas emisoras. Uno de los radialistas de la emisora Santa Rosa Estéreo cuenta:

Tuve una experiencia que no le deseo a nadie. La historia es que hace cinco años nuestro director fue secues- trado por el Ejército de Liberación Nacional; la guerrilla se lo llevó para la Serranía de San Lucas a quince horas de camino. Apenas llegó la noticia, en la emisora emprendimos una labor de información donde se le pedía a los captores que lo mantuvieran sano y salvo, que lo respetaran como un ciudadano de la población civil. Al principio no pensamos sacar la noticia al aire por el alboroto que podía ocurrir con el medio. Pero después de discutirlo decidimos sacar un comunicado al aire y empezaron todas las comunidades de las veredas a mandar cartas, a mandar mensajes donde solicitaban a la guerrilla que no le hicieran nada a José Botello, el director de la emisora. Recogimos más de mil cartas, más de dos mil firmas en un comunicado que se le envió a la Presidencia y al mismo grupo guerrillero (Radialista, 2004).

La emisora transmite todos los mensajes. En un acto provocador, de modo que la guerrilla le envía un mensaje a la emisora, diciendo que si es tanto el apoyo popular a Bote1lo, que vengan todos por él.

La emisora empezó a trabajar y en seis horas convocamos a cuatrocientas ochenta personas que se ofrecieron a ir hasta allá; más de cuarenta carros, hombres, mujeres, niños, todos con banderas blancas. Salimos como a la media noche y llegamos allá como a las siete de la mañana. Usted miraba hacia atrás y la caravana parecía una culebrita de campesinos y gente del municipio. Llegamos a un retén de la guerrilla y no nos dejaban pasar, sacaron las armas, echaron disparos, los guerrilleros llamaron a sus superiores y decían que había mucha gente y que estaba llegando aún más y que eran muchos y que la carretera estaba totalmente copada y ellos no eran sino seis guerrilleros. Y nosotros que nos dejaran pasar porque necesitábamos ir a traer a nuestro líder, a un hijo del pueblo, así que dieron la orden: '!Déjenlos que sigan!'. Nos dieron la información: 'Está en tal parte, pero ustedes no pueden llegar allá porque hay zona minada'. Y respondimos: 'Pues nosotros nos vamos para allá Llegamos a un pueblito. En todas las esquinas guerrilla. Solicitamos hablar con el comandante guerrillero y nos respondieron que no estaba, que esperáramos; inmediatamente nosotros hicimos cambuche [un refugio] y nos quedamos esa noche allí. Al día siguiente apareció el mentado comandante y le dijimos que nosotros veníamos por nuestro líder, una persona muy honesta, trabajadora y que necesitábamos que nos lo entregara no solamente porque la familia lo necesitaba sino todo un pueblo, así como ellos lo estaban viendo. Él no supo qué responder en el momento y dijo: 'Tengo que comunicarme con mi superior a ver .... Le respondieron: 'Dígales que se estén allí , a ver si de pronto se regresan'. 
Supimos porque hablaban por un radio y se escuchaba. No, nosotros llevábamos ollas, papas, yuca y ese día compramos una novilla y nos quedamos hasta que nos resolvieran el problema. Elegimos una comisión negociadora y finalmente se llegó a un acuerdo y lo liberaron. Siempre fueron siete días de calvario, pero llegó nuevamente el director a la emisora y eso fue fiesta, dos, tres días de fiesta y armonía, todo transmitido por la emisora Santa Rosa Estéreo (Radialista 2004).

De este caso es importante resaltar un par de elementos. Por un lado, la experticia de quienes estaban en la emisora en el momento del secuestro. Obviamente la emisora no tenía ningún tipo de lineamientos para saber cómo proceder en un caso como este. Sin embargo estos comunicadores comunitarios, en cuestión de minutos, tomaron decisiones fundamentales. Decidieron que el caso del secuestro de José Botello era un suceso público, que afectaba no sólo a la familia del secuestrado, sino a toda la comunidad. En el momento en que el secuestro pasa a ser un acontecimiento público, la emisora comienza a cubrir el evento desde dos frentes: primero, un periodismo comprometido con la información veraz y confiable y segundo, una campaña pública a favor de Botello, diseminada desde la emisora. Podemos ver, asimismo, los mismos elementos de los casos anteriores: un equipo de radialistas comunitarios que detectan cómo se abre un espacio comunicativo, detectan las necesidades de información y comunicación que surgen en la comunidad en el momento del secuestro, y utilizan su experticia para responder a esas necesidades desde las tecnologías con las que cuentan.

\section{Caso cuatro: Caquetá, Bárbara Charanga}

El cuarto caso que quisiéramos presentar aquí tiene que ver con la idea de utilizar los medios para transformar imaginarios colectivos. Pero primero, un poco de contexto. Belén de los Andaquíes está localizado en el piedemonte amazónico. Aquí llegaron desde los años cincuenta diferentes olas de migrantes de otras regiones colombianas. Los migrantes llegan y encuentran una región selvática y en su afán por replicar lo que habían dejado atrás, comienzan a tumbar selva, abrir potreros y meter ganado. Sin embargo en esta región la tierra no es apropiada para la ganadería, ni siquiera para la agricultura. La ganadería es nefasta para los ríos y los bosques del Caquetá. Y sin embargo desde los años cincuenta, la ganadería se ha convertido en la aspiración de todos, a punta de políticas públicas y de imaginarios culturales donde ser ganadero es la imagen del triunfador.

En el siguiente testimonio vemos reflejado este tipo de imaginario sobre la región; quien habla es un migrante que narra la colonización del rio Losada:
Había árboles de treinta y cuarenta metros de alto a los que se les daba hacha desde las seis de la mañana y al medio día seguían en pie. Pero eso sí, cuando caían descuajaban media hectárea porque uno ya había picado los palos más pequeños. Esa es otra cosa que usted no ha visto. Ver caer un árbol de esos es aterrador. Los animales corren, los pájaros chillan y la tierra tiembla. Eso es miedoso si uno no está acostumbrado (Arcila Niño, González et al. 2000, pp. 136-137).

Ahora veamos la versión del mismo territorio que circula gracias a Radio Andaquí. Es el mismo árbol, pero desde una versión otra, cultivada desde la radio comunitaria:

Azulejo: se alimenta de frutas. Carpintero: con el pico perfora árboles para construir el nido. Mochilero: tejedor de mochilas para que navidad sea todo el año. Mirlo: buscador de lombrices, artesano del barro. Diferentes colores, variado tamaño, voces distintas; la misma lucha por la vida en un solo árbol. Bárbara Charanga, una serie sobre cómo aprovechar nuestras diferencias para ponernos de acuerdo" (Radio Andaquí, 2003).

Esta otra versión del árbol apunta a un imaginario colectivo de la región muy diferente del 'Caquetá bueno para la ganadería'. En su versión de territorio, Radio Andaquí propone un imaginario colectivo enamorado de los árboles, el árbol pasa de ser un estorbo para la ganadería a ser un hábitat de muchas especies, un hogar del que muchos dependen.

\section{Caso cinco: Egipto y la primavera árabe}

El siguiente caso surge de los estudios realizados por la investigadora Merlyna Lim sobre la Primavera árabe y el uso de tecnologías de información y comunicación (TICs). Mientras que nos quieren hacer creer que estamos entrando en una era de revoluciones tipo Twitter o Facebook (Axford 2011, Gladwell 2010, Howard and Hussain 2011, Khondker 2011, Zhuo, Wellman and Yu 2011), los estudios de Lim en Túnez y Egipto revelan otra cosa. No son las tecnologías las que generan estos movimientos. Son comunicadores comunitarios que se ingenian formas de utilizar las tecnologías para responder a las necesidades de información y comunicación de activistas y movimientos sociales. Es un tipo de comunicación comunitaria más militante que los casos anteriores, pero en últimas el proceso es el mismo. La investigación de Lim sobre el levantamiento en Egipto, que los medios han convertido en el caso ejemplar de la llamada Revolución 2.0, revela cómo lo que apareció en los medios como una revolución instantánea gracias a las TICs, se había estado construyendo por años (Lim, 2012). Lim demuestra que si nos enteramos de los eventos en la Plaza Tahir gracias a Facebook y Twitter fue porque no está- 
bamos prestando atención al movimiento conocido con las doce horas de protesta del 2003, o el Movimiento Kefaya del 2004, o las protestas estudiantiles del 2006, en suma, todas éstas acciones políticas de la disidencia que se fueron intensificando hasta producir las manifestaciones del 2011 (Lim, 2012). En segundo lugar, Lim demuestra cómo los movimientos sociales van aprendiendo a utilizar las TICs de otros movimientos sociales. En Egipto, el tan famoso uso de Twitter del movimiento del 2011 fue adoptado de un movimiento de algunos años atrás, llamado el Movimiento Juvenil 6 de Abril (Lim, 2012).

En tercer lugar, Lim demuestra que las TICs nunca son suficientes para responder a todas las necesidades de información y comunicación de un movimiento social. Los movimientos sociales requieren de una comunicación compleja, que incluye una multiplicidad de formas, desde la comunicación performativa de las personas de carne y hueso en la calle, la consolidación de redes para que la información se mueva horizontal y verticalmente al mismo tiempo, los procesos unidireccionales de transmisión de información, a la comunicación interpersonal. En Egipto, Lim identifica cómo los taxistas y vendedores de comida fueron puntos clave de transmisión de información, así como los estadios de fútbol, los cafés, y las mezquitas (Lim, 2012).

De todo esto nos queda: primero, que la comunicación que necesita un movimiento social es compleja; el acceso a TICs es importante, pero no podemos olvidar las otras formas de comunicación. Además, el entusiasmo con los medios de redes (Facebook, Twitter, YouTube) tiene que hacer conciencia de que, a diferencia de una radio o una imprenta, estas nuevas tecnologías no pueden cortar el cordón umbilical que las une a sus padres corporativos, con los problemas de vigilancia y censura que esto conlleva.

¿Qué ocurre al mirar todos estos casos desde la comunicación para el cambio social? Vamos a comenzar con un recuento histórico de este campo, con el fin de dejar claro el marco conceptual que vamos a desarrollar.

\section{LAS DOS VERTIENTES HISTÓRICAS}

Recordemos las dos vertientes históricas que han dado forma a lo que hoy llamamos comunicación para el cambio social. Por un lado, la tradicional escuela de la comunicación para el desarrollo, inspirada en los planteamientos de Daniel Lerner y Walter Rostow, sobre las políticas económicas necesarias para eliminar la pobreza del tercer mundo. Según Lerner y Rostow, la pobreza del tercer mundo se remediaría si los países desarrollados pudieran darle una mano a los países sub-desarrollados y ayudarlos a modernizarse y a dejar de lado la mentalidad tradicional. En un texto brillante sobre el origen histórico de la teoría desarrollista, Carlos Cortes cita al presidente estadounidense Woodrow Wilson, quien en 1918 insistía: "Hay pueblos incapaces aún de administrarse ellos mismos en las condiciones especialmente difíciles del mundo moderno [...] El mejor método es confiar la tutela de estos pueblos a las naciones desarrolladas".

Muy pronto los expertos que intentaban 'desarrollar' a las comunidades tercermundistas descubrieron el gran potencial de los medios masivos de comunicación. ¿Qué mejor que estas tecnologías para difundir las ideas, los estilos de vida y la tecnología del primer mundo al tercer mundo? Wilbur Schramm, uno de los principales líderes de esta corriente insistía en el rol de los medios de comunicación masiva para 'modernizar' a los 'sub-desarrollados'.

Así nace la primera escuela, conocida desde entonces como la comunicación para el desarrollo. Una de las principales líneas de acción e investigación de esta escuela es el modelo de difusión de innovaciones. Liderada por el estadounidense Everett Rogers, la difusión de innovaciones funciona desde una comunicación para la persuasión. Años después, inspirado en el trabajo del mexicano Miguel Sabido, Rogers desarrollaría el edu-entretenimiento, otro acercamiento a la comunicación para el desarrollo con el fin de persuadir audiencias.

\section{Esto es comunicación para el cambio social: un acercamiento a la comunicación que nos inserta dentro de la comunidad, nos obliga a mirar a la comunidad desde sus necesidades de comunicación e información.}

De la comunicación para el desarrollo aprendimos cómo los medios masivos se pueden utilizar en campañas públicas para difundir ideas que van desde la necesidad de vacunar a los niños contra el polio, hasta las opciones que las mujeres tienen para controlar su fertilidad. Así mismo, la comunicación para el desarrollo nos dejó una serie de líneas de acción que incluyen la comunicación estratégica, el cabildeo de medios, y el edu-entretenimiento.

Por otro lado, también hacia los años setenta, surge en América Latina otra forma de pensar la comunicación. Inspirada en los planteamientos pedagógicos de Paulo Freire, esta comunicación otra no se piensa como transmisión de información, y ni siquiera como emisión de mensajes desde un emisor hacia un receptor, sino más bien en términos de diá- 
logo y construcción de sentido. La comunicación se asume como el poder que tiene (o no tiene) un sujeto de usar el lenguaje para nombrar y transformar el mundo en sus propios términos. El asumir que existe una estrecha relación entre lenguaje y poder es una idea fundamental de esta comunicación otra. Es decir, quien tiene el poder de nombrar y expresar la realidad tendrá así mismo el poder de definir cuál es el problema y por lo tanto cuál es la solución a ese problema. En básica del sujeto tercermundista. Sólo cuando el sujeto se pueda apropiar de los lenguajes y los medios para nombrar el mundo en sus propios términos, podrá hacer un diagnóstico de su realidad y diseñar sus propias soluciones.

Para esta comunicación otra también fueron relevantes los aportes de la peruana Rosa María Alfaro, el chileno/ belga Armand Mattelart, el boliviano Luis Ramiro Beltrán, los argentinos Marita Mata y Eliseo Verón, el mexicano/ argentino Néstor García Canclini, el uruguayo Mario Kaplún y por supuesto, nuestro colombiano Jesús Martín Barbero. Todos ellos desarrollaron planteamientos pioneros para pensar el futuro de la región desde la cultura y la comunicación pero sobretodo, desde sí misma, es decir, desde la experiencia misma de las comunidades latinoamericanas. A esta escuela se le conoció en su momento como la comunicación alternativa. este sentido, la comunicación se piensa como una necesidad

\section{LOS ENFRENTAMIENTOS}

Hacer un recuento de los enfrentamientos, choques y guerras entre la comunicación para el desarrollo y la comunicación alternativa en los últimos treinta años sería cosa de nunca acabar. En foros académicos que iban desde las conferencias de la International Communication Association hasta las reuniones de la Semana Internacional de la Comunicación convocadas por FELAFACS, investigadores y profesores de comunicación defendieron una $u$ otra escuela, discutieron, argumentaron, se insultaron y salieron de cada uno de estos debates convencidos de tener la razón. A nivel de práctica se dieron debates parecidos, dentro de organizaciones internacionales para el desarrollo, tales como el Banco Mundial, UNESCO, USAID, donde expertos en desarrollo defendían proyectos e iniciativas diseñadas desde uno u otro marco teórico.

La comunicación para el desarrollo es atacada por la comunicación alternativa por ser una comunicación vertical, donde el receptor está limitado a ser un "recipiente vacío" que recibe mensajes sin poder decir nada. El emisor, precisamente porque asume que el receptor no tiene nada que decir, diseña mensajes sin siquiera conocer las necesidades, sueños, lenguajes, o estéticas del receptor. Para el receptor estos mensajes son ajenos a su entorno, poco tienen que ver con su realidad social y cultural. Gran parte de la crítica se enfoca en la escuela de la difusión de innovaciones, que es atacada por imperialista, por tratar de difundir ideas, estilos de vida, formas de vivir la vida de contextos de países desarrollados entre comunidades tercermundistas. Uno de los ataques más comu-

Parte de este acercamiento a la comunicación es toda la línea de investigación en medios alternativos, comunitarios y ciudadanos. Si la necesidad prioritaria de los pueblos tercermundistas es aprender a hablar en sus propios términos, desarrollar voces fuertes para nutrir las esferas públicas con ideas y propuestas, apropiarse de las tecnologías de información y comunicación para llevar voces de la margen al centro, qué mejor que los medios comunitarios para llevar a cabo estos objetivos (Alfaro 1985, Kaplún 1983, Simpson Grinberg 1981)?

En conclusión, los años setenta nos dejan con dos escuelas de comunicación muy diferentes: por un lado, la comunicación para el desarrollo y por otro lado, la comunicación alternativa. No pasó mucho tiempo antes de que estas dos escuelas chocaran en fuertes enfrentamientos. nes a este tipo de comunicación es su función de persuadir y manipular. el mercadeo social, el edu-entretenimiento, las campañas públicas se critican como usos de la comunicación y de los medios con el fin de convencer al emisor de cambiar sus comportamientos, actitudes, ideas. Y finalmente, la comunicación para el desarrollo es atacada por concebir el cambio social a muy corto plazo; se hace un diagnóstico, se diseña una estrategia, y se espera un resultado un año más tarde. Desde la comunicación alternativa se plantea que siglos de marginalidad, relaciones coloniales de dependencia, y pobreza extrema no se solucionan en unos meses y ni siquiera en unos años. Desde la comunicación alternativa el cambio social se concibe como algo que debe permear lo más profundo de las culturas locales y los tejidos sociales, y por tanto algo que toma tiempo, a veces varias generaciones. 
La comunicación alternativa es atacada por la comunicación para el desarrollo por ser una comunicación ineficiente, donde rara vez se sabe si la meta del proyecto se logró o no. Surgen cuestionamientos múltiples: ¿Cómo se mide el empoderamiento? ¿Cómo se sabe si una comunidad se ha apropiado de sus lenguajes o no? ¿Cómo se evalúa un proyecto que intenta mover voces marginales hacia el centro de las esferas públicas? Uno de los grandes cuellos de botella, sin duda, es la cuantificación de este tipo de variables, especialmente en términos de cómo realizar las evaluaciones de los proyectos. Por otro lado, la comunicación alternativa también es atacada porque desiste de cualquier papel que puedan jugar los medios masivos en procesos de cambio social. Sólo se piensa desde los medios alternativos, comunitarios y ciudadanos.

Aún hoy en día estos debates continúan y los ataques siguen yendo y viniendo. Sin embargo, quisiéramos proponer un tercer camino; porque mirando los casos arriba mencionados desde los dos paradigmas de comunicación para el desarrollo y comunicación alternativa, es hora de re-definir el campo de la comunicación para el cambio social desde una perspectiva más incluyente.

\section{LA UTOPÍA}

Ahora pensemos desde una utopía. Desde los cinco casos de comunicación en la comunidad presentados arriba, ¿qué forma tendría un centro de comunicación comunitaria y ciudadana? Es decir, pensando desde las necesidades de información y comunicación de una comunidad, icómo concebir un centro de comunicación comunitaria ideal, utópico? Imaginemos una comunidad de unos 90mil habitantes, un centro urbano rodeado de áreas rurales. Aquí funciona un nuevo centro de comunicación comunitaria. $\mathrm{Si}$ lo pensamos en función de las necesidades de información y comunicación de la comunidad, el centro debería incluir las siguientes líneas de acción:

1. Una Comunicación para la Participación y el Empoderamiento: donde se fortalecen iniciativas de medios ciudadanos. El centro incluye una emisora comunitaria, una escuela de producción de video y televisión que nutre un canal local de televisión por cable y un impreso que sale cada mes, en papel y en versión virtual. Estos medios se asumen como vehículos para la participación ciudadana. De Guillermo Pérez en Inírida podemos aprender cómo utilizar los medios comunitarios para cultivar un tejido social de diálogo. Las parrillas de programación se piensan como un espejo de la diversidad cultural local. La idea es que estos medios se conviertan en lugares de expresión de identidades locales, a través de lenguajes y formas de narrar locales, que nutran una esfera pública de diálogos entre diferencias. Además, estos medios se definen así mismo como escuela, cultivando desde la niñez una voz propia que narra las cotidianidades y que entra en diálogo con otras voces en la esfera pública.

Esta línea de acción sería responsable por diseñar estrategias de producción participativa de medios al estilo del El Cuarto con Dios. Aquí se trata, primero, de una comunicación para el empoderamiento. Y segundo, una comunicación que se propone nutrir las esferas públicas de voces locales que entran en diálogo.

2. Nuestro centro también contaría con un equipo dedicado a las campañas públicas: donde se utilizan los medios (todos los medios, masivos, comunitarios y de redes sociales) para informar o persuadir a audiencias sobre asuntos de interés local. Es otro tipo de comunicación, lineal, vertical, pero también necesaria. Por ejemplo el caso del concurso navideño en Belén de los Andaquíes es una estrategia de tipo campaña pública; es una comunicación pensada desde la persuasión. Así mismo, el ejemplo del spot de Bárbara Charanga sobre el árbol y los pájaros, es una comunicación no participativa, pero que pretende posicionar mensajes marginales en el centro. Estas campañas, podría decirse, son diseñadas un poco desde el edu-entretenimiento, donde se utilizan géneros y formas de narrar de la cultura popular local para crear productos mediáticos que informen, persuadan, o provoquen discusiones públicas sobre ciertos temas.

Las campañas se diseñarían desde una versión local del asunto tratado. Por ejemplo, si es una campaña ambientalista, se diseña en torno a problemáticas locales que afectan el medio ambiente. El equipo encargado de esta línea de acción deberá tener conocimientos bien afianzados en el diseño y ejecución campañas públicas, mercadeo social y edu-entretenimiento.

3. La tercera línea de acción de nuestro centro es un equipo de cabildeo de medios: este equipo sería responsable de todo lo que tiene que ver con comunicación y movilización. Es el equipo encargado de diseñar la estrategia que logró movilizar a la comunidad para el rescate de José Botello, por ejemplo. Es una comunicación que incluye formas verticales de comunicación (usar los medios para informar a la comunidad de lo que está pasando) pero también formas horizontales (activar redes sociales para que la información vaya pasando de boca en boca, como en el caso egipcio de la primavera árabe). Lo que se busca es que los medios lleven los temas de la movilización a la esfera pública. Es una estrategia eficiente para ampliar la agenda pública con temas y asuntos que podrían quedarse relegados a la marginalidad. Este equipo estaría al 
servicio de organizaciones sociales, grupos populares, colectivos de activistas y movimientos sociales locales y regionales (por ejemplo, la asociación local de pescadores, grupos de mujeres, el movimiento de ambientalistas que lucha contra la entrada de transnacionales mineras en la región), proponiendo una serie de estrategias diseñadas para movilizar a la ciudadanía y posicionar las propuestas de estos grupos y colectivos en los medios masivos locales y regionales. Los movimientos sociales se están la comunicación cada vez más en serio. Por ejemplo Educación 2020, una ONG dedicada a apoyar el movimiento estudiantil chileno que luchaba en contra de la privatización de la educación universitaria en el 2011, cuenta con un equipo de varios comunicadores dedicados exclusivamente a manejar las estrategias de comunicación para la movilización (Waissbluth 2012).

4. La última línea de acción del centro es el periodismo. ¿Se necesita del periodismo en la comunicación comunitaria? ¡Claro que sí! En el caso del rescate de José Botello es claro que un buen periodismo local jugó un papel clave. Por eso, nuestro centro contará con un equipo de reporteros ciudadanos. Este equipo deberá manejar muy bien los principios fundamentales del periodismo en términos de verificación de la información, selección de fuentes, autonomía, interés público y responsabilidad social. Además, este equipo debe tener una fuerte capacitación en periodismo: cómo realizar una entrevista, escribir una crónica, hacerle el seguimiento a una noticia. Los comunicadoresperiodistas ciudadanos encargados de esta línea de acción podrían tener una relación muy estrecha con la Fundación para el Nuevo Periodismo Iberoamericano (http:// www.fnpi.org/), donde recibirán frecuentemente talleres de maestros como Alma Guillermoprieto o Javier Darío Restrepo sobre ética del periodismo, reportaje audiovisual, periodismo literario, o periodismo gráfico. Incluso, el equipo periodístico podría ser reconocido y apoyado por organizaciones nacionales como la Fundación para la Libertad de Prensa (FLIP) o la organización de Medios para la Paz.

5. Por último, nuestro centro contará con una tienda comunicativa: donde se ofrezcan servicios básicos como la toma e impresión de fotos para pasaportes y otros documentos oficiales, impresión y fotocopiado, café Internet y suministro de insumos básicos de papelería. Se ofrecerán además toda una gama de servicios que tienen que ver con la comunicación, desde la producción radial o audiovisuales, hasta la producción de eventos, conciertos, o el diseño de campañas y piezas publicitarias para organizaciones locales (por ejemplo, el hospital local acude a nuestro centro para que le diseñe una campaña sobre salud sexual y reproductiva, o una agencia internacional que trabaja en la región le pide al centro que le diseñe una serie de materiales, desde afiches hasta spots radiales sobre el retorno de familias que fueron desplazadas por el conflicto armado). La tienda será además un lugar de encuentro donde se dan cita los colectivos de comunicación, los grupos sociales, y los 'gomosos' de la comunicación, los medios y las TICs.

\section{CONCLUSIÓN}

Visto así, el campo de la comunicación para el cambio social se va delineando como un campo complejo y diverso. Un campo que surge a medio camino entre la comunicación para el desarrollo y la comunicación alternativa. Un campo que toma lo mejor de estas dos tradiciones, pero no se casa con las verdades absolutas de ninguna. Así, por ejemplo, asume que en contextos locales, una comunidad va a necesitar diseñar sus propias campañas públicas, usando medios masivos para persuadir, pero, a diferencia de las campañas de la Comunicación para el Desarrollo tradicionales, los mensajes persuasivos se diseñan desde dentro de la comunidad, desde los lenguajes y estéticas locales, y siempre acerca de problemáticas locales, nunca desde una mirada externa.

El principal viraje que permite el surgimiento de una tercera vía, es el pensar desde las necesidades de información y comunicación de las comunidades, en vez de pensar desde las verdades últimas de una teoría de la comunicación. Es decir, en vez de pensar si es verdad o no que la comunicación para el desarrollo persuade y manipula, se trata de reconocer que en las comunidades, en momentos históricos específicos, surgen necesidades y problemas que se pueden resolver a través de acciones comunicativas de persuasión. Mientras que es obvio que una comunidad necesita mucho más que recibir mensajes persuasivos enviados desde el exterior, también es cierto que en la vida de cualquier comunidad, hay momentos donde se necesitan mensajes persuasivos que lleguen a un público de forma rápida y eficiente. Obviamente, esto no agota el quehacer comunicativo que necesita la comunidad; sin embargo, es una línea de acción importante. Así mismo, pensando desde las necesidades de información, comunicación y movilización de una comunidad, es claro que en ciertas circunstancias concretas, será necesaria una comunicación performativa, o una comunicación que genere procesos de redes sociales, o una comunicación que proponga a punta de entretenimiento, o una comunicación periodística. Es hora de replantear el campo de la comunicación para el cambio social desde una mirada incluyente y diversa, que acoja lo aprendido desde la comunicación para el desarrollo y también desde los aprendizajes de la comunicación alternativa. 
Ahora, ¿quién va a formar estos comunicadores para el cambio social, comunicadores capaces de conectarse con las necesidades de información, comunicación y movilización de las comunidades, comunicadores expertos en comunicación participativa, comunicación para la movilización, edu-entretenimiento, cabildeo de medios, diseño de campañas, periodismo, producción y programación de medios? En el 2006, en un artículo para Media Development, Alfonso Gumucio Dagron y Clemencia Rodríguez realizaron un inventario de los programas de comunicación para el cambio social. Tarea fácil, porque eran muy pocos, poquísimos. En ese entonces existían trece programas, contando cuatro programas a nivel de licenciatura en Argentina, Bolivia, Perú y Jamaica; ocho programas a nivel de maestría en: EEUU, Canadá, Australia, India, Zambia, España, Suecia y Colombia. El único país que cuenta con un programa de comunicación para el cambio social que incluye licenciatura, maestría y doctorado es Filipinas, en la Universidad de los Baños ${ }^{1}$. Es prometedor que la Universidad Minuto de Dios en Colombia y Temple University en Estados Unidos están inaugurando nuevos programas en comunicación para el cambio social. La Santo Tomás en Colombia está diseñando programas de maestría, así como la Universidad Landivar en Guatemala. Pero no hay mucho más.

Es triste pensar que existe tan poco interés en nuestras universidades para ocuparse, precisamente, de la comunicación responsable de las necesidades de información y comunicación de nuestras comunidades.

$\mathbf{1}$ "The main reference in this group of academic institutions is the College of Development Communication at the University of The Philippines, in Los Baños. In the last twenty years this College has grown from a small department within the Faculty of Agriculture, to a full-blown college that offers an undergraduate programme, and masters and PhD degrees in Communication for Development. Most of these programs are located in Latin America \& the Caribbean in universities such as Universidad de La Plata (Argentina), Universidad Andina Simón Bolivar (Bolivia), Pontificia Universidad Católica del Peru (Peru), Universidad del Norte (Colombia), Universidad de las Americas in Puebla (Mexico) and University of West Indies (Jamaica). In North America, two universities have similar departments: Ohio University at Athens (USA) and the University of Guelph (Canada). Several programmes have been created in Europe, at Malmo University (Sweden) and Universidad de Sevilla (Spain). We only know of one masters degree in Communication for Development in Africa, at the University of Zambia, one in India at the G.B. Pat University of Agriculture and Technology, in Pantnagar, and a masters program in Communication for Social Change at the University of Queensland in Australia" (Gumucio Dagron y Rodríguez, 2006).

\section{REFERENCIAS}

Alfaro M. Rosa María. (1987). Ciudadanos de a de veras. Un enfoque comunicativo de la vigilancia ciudadana de la gestión pública. Calandria, segunda edición.

Alfaro M. Rosa María. (1987). "Usos Sociales Populares De La Telenovela En El Mundo Urbano”. En Serie Informe e Investigación, No. 1. Calandria.

Alfaro M. Rosa María. (1987). "La pugna por la hegemonía cultural en la radio peruana”. Revista Diá-logos de la Comunicación No. 18, FELAFACS, Lima.

Alfaro M. Rosa María. (1986). "Talleres de dramatización popular: educar desde los sujetos y en los procesos”. Revista Tarea No. 15, Lima.

Alfaro M. Rosa María. (1986). “Telenovela, Cultura Cotidiana De Las Masas Latinoamericanas". En Revista El Zorro de Abajo No. 4.

Alfaro M. Rosa María. (1985). Los Altoparlantes, Recuperación de la Palabra Popular. Mimeo. Calandria.

Alfaro M. Rosa María. (1988). De la conquista de la ciudad a la apropiación de la palabra. Calandria Tarea. Segunda edición.

Arcila Niño, Oscar, Gloria Gonzalez, Franz Gutiérrez, Adriana Rodríguez, and Carlos Ariel Salazar. (2000). Caquetá: Construcción de un Territorio Amazónico en el Siglo XX. Bogotá: Instituto Amazónico de Investigaciones Científicas, SINCHI.

Axford, Barrie. (2011) "Talk About a Revolution: Social Media and the MENA Uprisings”. Globalizations 8(5): pp. 681-686.

Beltrán, Luis Ramiro. (1976). "Alien Premises, Objects, and Methods in Latin American Communication Research". In Communication and Development. Critical Perspectives, edited by Everett M. Rogers, pp. 15-42. Beverly Hills: Sage.

Cortés, Carlos E. (2001). La comunicación al ritmo del péndulo: Medio siglo en busca del desarrollo. Documento no publicado.

Freire, Paulo (1973). Education for Critical Consciousness. New York: Seabury Press.

Freire, Paulo (1980). Educación como Práctica de la Libertad. Mexico: Siglo XXI.

García Canclini, Néstor (1988). Culture and Power: The State of Research. Media, Culture and Society 10:467-497.

García Canclini, Néstor (1989). Las Cultures Populares en el Capitalismo. Mexico: Nueva Imagen.

García Canclini, Néstor (1990). Culturas Híbridas. Mexico: Grijalbo.

García Canclini, Néstor (1992). “Cultural Reconversion”. In On Edge: The Crisis of Contemporary Latin American Culture, edited by George Yúdice, Jean Franco, and Juan Flores, Juan, pp. 29-43. Minneapolis: University of Minnesota Press. 
Gladwell, Malcolm (2010). "Small Change. Why the Revolution will not be twitted”. The Newyorker. Retrieved from http:// www.newyorker.com/reporting/2010/10/04/101004fa_ fact_gladwell. Accessed December 8, 2013.

Gumucio Dagron, Alfonso and Rodríguez, Clemencia. (2006). "Time to call things by their name". Media Development 3, 9-16. (Available at http://www. waccglobal.org/en/20063-communication-for-developmentand-social-justice/586-Time-to-Call-Things-by-Their-NameThe-Field-of-Communication--Social-Change.html).

Howard, Philip y Hussain Muzammil. (2011) "The Role of Digital Media”. Journal of Democracy 22(3): 35-48.

Kaplún, Mario. (1983). “La Comunicación Popular”. Alternative Válida, Chasqui, 7:pp. 40-43.

Kaplún, Mario (1986). "Uruguay: participación, praxis, problema. La Experiencia del Casete-Foro”. In Comunicación Alternativa y Cambio Social: América Latina, ed. Máximo Simpson Grinberg, pp. 266-283. Mexico: Premià Editora (Second Edition).

Khondker, Habibul (2011) "Role of the New Media in the Arab Spring”. Globalizations 8(5): pp. 675-679.

Lerner, Daniel (1967). Communication and the Prospects of Innovative Development. In Communication and Change in the Developing Countries, edited by Daniel Lerner and Wilbur Schramm, pp. 305-322. Honolulu: East-West Center Press.

Lim, Merlyna (2012). "Clicks Cabs, Coffee Houses: Social Media and the Oppositional Movements in Egypt (20042011)”. Journal of Communication, 62: pp. 231 - 248.

Martin Barbero, Jesús (1987a). "Comunicación, pueblo y cultura en el tiempo de las transnacionales. En Comunicación y Culturas Populares en Latinoamerica, (son autor), pp. 38-50. Mexico: FELAFACS.

Martin Barbero, Jesús (1987b). De los Medios a las Mediaciones. Mexico: Gustavo Gili.

Martin Barbero, Jesús (1993). "Latin America: Cultures in the Communication Media”. Journal of Communication 42(2): pp. 18-30.

Martin Barbero, Jesús and Sonia Muñoz, eds (1992). Television y melodrama. Bogotá: Tercer Mundo Editores.

Matterlart, Armand (1972). Agresión desde el espacio. Cultura y napalm en la era de los satélites. Chile: Ediciones Universitarias de Valparaiso.

Matterlart, Armand (1973). Medios de comunicación: mito burgués versus lucha de clases. Bogotá: Aquelarre.

Matterlart, Armand (1974a). La comunicación masiva en el proceso de liberación. Buenos Aires: Siglo XXI.

Matterlart, Armand (1974b). Las transnacionales y la comunicación de masas. Quito: Editorial Universitaria.
Matterlart, Armand (1977). multinacionales y sistemas de comunicación. Los aparatos ideológicos del imperialismo. Mexico: Siglo XXI.

Matterlart, Armand (1981). Comunicación y nueva hegemonía. Lima: CELADEC-CEDEE.

Matterlart, Armand. (1983). Transnationals and the Third World. Massachusetts: Bergin \& Garvey Publishers, Inc.

Mattelart, Armand, Mattelart, Michelle, and Piccini, Mabel (1977). Los medios de comunicación de masas. La ideología de la prensa liberal. Caracas: El Cid Editor.

Pasquali, Antonio (1963). Comunicación y cultura de masas. Caracas: Monte Ávila Editores.

Pasquali, Antonio (1979). Comprender la comunicación. Caracas: Monte Ávila Editores.

Pérez, Guillermo. (2004). "Entrevista con Clemencia Rodríguez", Bogotá.

Radialista de Santa Rosa Estéreo (2004). "Entrevista del taller de evaluación de AREDMAG”, Bucaramanga.

Radio Andaquí (2003). "Promo - Barbara Charanga. Belén de los Andaquíes”, Colombia. Grabación.

Rodríguez, Clemencia (2011) Citizens' Media against Armed Conflict: Disrupting Violence in Colombia. Minneapolis: The University of Minnesota Press.

Rogers, Everett M (1962). Diffusion of Innovation. New York: Free Press of Glenco.

Rogers, Everett M (1969). Modernization Among Peasants. New York: Holt, Reinhart and Winston.

Rogers, Everett M (1976). “Communication and Development: The Passing of the Dominant Paradigm”. In Communication and Development. Critical Perspectives, edited by Everett M. Rogers, pp. 121-148. Beverly Hills: Sage.

Rogers, Everett M (1983). Diffusion of Innovation. New York: The Free Press.

Rogers, Everett M (1997). “Communication Study in North American and Latin America”. Paper presented at the First Annual Communication Conference of the Americas (sponsored by SCA and FELAFACS), February 1-4, Mexico City.

Rostow, Walt W. (1978). The World Economy: History and Prospect. New York: MacMillan.

Schramm, Wilbur (1964). Mass Media and National Development. The Role of Information in the Developing Countries. Stanford: Stanford University Press and Paris:UNESCO.

Simpson Gringberg, Máximo (ed.) (1981). Comunicación alternativa y cambio social en América Latina. Mexico: Universidad Nacional Autónoma de Mexico.

Verón, Eliseo (1976a). "Introducción: hacia una ciencia de la comunicación social”. In Lenguaje y Comunicación Social, pp. 9-29. Buenos Aires: Ediciones Nueva Visión. 
Verón, Eliseo (1976b). "Ideología y comunicación de masas: la semantizacion de la

violencia política”. En Lenguaje y Comunicación Social, pp. 133187. Buenos Aires: Ediciones Nueva Visión.

Waissbluth, Mario (2012). "La construcción de un movimiento ciudadano efectivo". Tomado de: http://www.youtube.com/ watch? $=$ ktlpCCFacIk.

Zhuo, Xiaolin,Wellman, Barry y Yu, Justine (2011). "Egypt: The First Internet Revolt?” Peace Magazine 27(3): pp. 6. 